Apresentação

Hegemonia - Revista Eletrônica do Programa de Mestrado em Direitos Humanos, Cidadania e Violência/Ciência Política do Centro Universitário Unieuro

ISSN: 1809-1261

UNIEURO, Brasília, número 27 (Especial), 2019, pp. 1-6.

Expediente

Hegemonia/ Revista Eletrônica do Programa de Mestrado em Direitos Humanos, Cidadania

e Violência do Centro Universitário UNIEURO - ISSN: 1809-1261, número 27 (Especial), 2019

Editora

Centro Universitário Unieuro

Administração

Reitor: Edson Luiz Zangrando Figueira, Dr.

Editor:

Professor Carlos Domínguez Avila, Doutor - Centro Universitário UNIEURO

Endereço para Correspondência:

Centro Universitário - UNIEURO

SCES - Trecho 0 conj. 05 - Avenida das Nações Sul

70.200-001 - Brasília, DF

Tel. (61) $3445-5888$

E-mail: hegemonia@unieuro.com.br

Site: www.unieuro.edu.br 
Apresentação

Hegemonia - Revista Eletrônica do Programa de Mestrado em Direitos Humanos, Cidadania e Violência/Ciência Política do Centro Universitário Unieuro

ISSN: $1809-1261$

UNIEURO, Brasília, número 27 (Especial), 2019, pp. 1-6.

Sumário

Apresentação

USO DE FOTOTERAPIA PARA CICATRIZAÇÃO DE FERIDAS DE PÉS DIABÉTICOS

Franciéle de Matos da Silva, Lorena de Sousa Moreira, Mayla dos Santos Silva,

Wellington Rodrigues e Suélia de Siqueira Rodrigues Fleury Rosa

LÁTEX COMO BIOMATERIAL E SUAS POTENCIALIDADES NA ÁREA MÉDICA

Maria do Socorro de Lima Silva, Ludmila Evangelista dos Santos, Glécia Virgolino

da Silva Luz, José Carlos Tatmatsu Rocha e Aldene Guimarães Duarte Dantas

O PROGRAMA NACIONAL DE PLANTAS MEDICINAIS E FITOTERÁPICOS, OS ARRANJOS PRODUTIVOS LOCAIS (APL'S) DAS AGRICULTORAS FAMILIARES

E AO ACESSO AO SISTEMA ÚNICO DE SAÚDE

Eliana Lutzgarda Collabina Ramirez Abrahão e Joseane Costa Carvalho

ASSISTÊNCIA A CRIANÇA E AO ADOLECENTE EM DIFERENTES FASE DA LEUCEMIA: APRENDIZAGEM DE NOVOS COMPORTAMENTOS COMO IMPACTO FAMILIAR

Adasildo Carvalho da Silva, Maria Fabiana de Castro, Marilia Forte Gomes e Marcella Lemos Brettas Carneiro 
Apresentação

Hegemonia - Revista Eletrônica do Programa de Mestrado em Direitos Humanos, Cidadania e Violência/Ciência Política do Centro Universitário Unieuro

ISSN: $1809-1261$

UNIEURO, Brasília, número 27 (Especial), 2019, pp. 1-6.

TRANSPLANTE DE MEDULA ÓSSEA EM PESSOAS COM DOENÇA FALCIFORME: UMA REVISÃO BIBLIOGRÁFICA

Jéssica Luciano da Costa, Aldira Guimarães Duarte Domínguez, Maria Inez Montagner e Miguel Ângelo Montagner

BIOSENSORES PARA DIAGNÓSTICO DE DOENÇAS CAUSADAS POR VÍRUS: UMA REVISÃO

Pedro Henrique Queiroz Miranda, Matheus Escovedo da Costa, Juliano Alexandre Chaker e Lourdes Mattos Brasil

INTERNAÇÕES E CUSTOS HOSPITALARES: ANÁLISE COMPARATIVA DE UM SISTEMA DE AUTOGESTÃO COM O SISTEMA ÚNICO DE SAÚDE

Débora Bleza Santos, Carla Pintas Marques e Marcos Takashi Obara

POLÍTICAS PÚBLICAS: ANÁLISE DO MODELO DE GESTÃO DO HOSPITAL DA CRIANÇA DE BRASÍLIA JOSÉ ALENCAR (HCB) NA ÁREA ODONTOLÓGICA

Cynthia Fernandes Bandeira Franco Americano, Larissa Rosa Teixeira Dias de Almeida Carvalho Martins e Larisa Ho Bech Gaivizzo

DOENÇA DE ALZHEIMER: UM OLHAR FRENTE AO CUIDADOR FAMILIAR

Juliana Cavalcante de Arêdo, Valeria Alves Ferreira Soares da Rocha e Iolanda Bezerra dos Santos Brandão 
Apresentação

Hegemonia - Revista Eletrônica do Programa de Mestrado em Direitos Humanos, Cidadania e Violência/Ciência Política do Centro Universitário Unieuro

ISSN: $1809-1261$

UNIEURO, Brasília, número 27 (Especial), 2019, pp. 1-6.

\section{A ADOÇÃO À LUZ DA LEI DE BIOSSEGURANÇA}

Alessandro Rezende da Silva e Ana Cláudia Silva de Melo

WHY IS EDUCATIONAL RESILIENCE IMPORTANT? HIGHER EDUCATION IN MARGINALIZED POPULATIONS IN MEXICO CITY

Rosa Ynés Alacio García

O NASCIMENTO DA ARTE DA CIÊNCIA POLÍTICA

Ângelo Roberto Rosa Ávila e Vicente Fonseca

NORMAS TRIBUTÁRIAS COMO INSTRUMENTO DE PRESERVAÇÃO AMBIENTAL

Aline Martins Ferreira e Cristina Melo Gonçalves

ÚLCERA DO PÉ DIABÉTICO (UDP) NO DLABETES MELLITUS 2: UMA ABORDAGEM MOLECULAR

Luna Alcântara Neres de Carvalho, Melissa Silva Monteiro e Marcella Lemos Brettas Carneiro

Normas para a apresentação de originais 
Apresentação

Hegemonia - Revista Eletrônica do Programa de Mestrado em Direitos Humanos, Cidadania e Violência/Ciência Política do Centro Universitário Unieuro

ISSN: 1809-1261

UNIEURO, Brasília, número 27 (Especial), 2019, pp. 1-6.

\section{DOSSIÊ: SAÚDE COLETIVA, POLÍTICAS PÚBLICAS E SOCIEDADE NO BRASIL: ESTUDOS INTERDISCIPLINARES}

\section{APRESENTAÇÃO}

O Dossiê "Saúde Coletiva, Políticas Públicas e Sociedade no Brasil: Estudos Interdisciplinares", aborda temas dos mais relevantes na área da saúde. Este volume compõese de discussões realizadas por um seleto grupo de pesquisadores e colaboradores, os quais são envolvidos e comprometidos com pesquisa e inovação tecnológica em saúde. Sabe-se que, constitucionalmente a Carta Magna apresenta a saúde como direito de todos e dever do Estado, no entanto, a garantia deste direito ainda dista muito de ser satisfatório, principalmente para os portadores de doenças crônicas e que dependem, único e exclusivamente, dos serviços oferecidos pelo sistema de saúde brasileiro. Assim, acredita-se que estudos propulsores de inovações tecnológicas em saúde, corroboram positivamente em melhorias relacionadas à variável custo benefício, e à promoção da qualidade de vida dos usuários do sistema.

Neste sentido, os artigos aqui dispostos abordam, cada um dentro de sua linha de pesquisa, as estratégias e argumentos que fundamentam os debates em torno da importância das políticas públicas para o atendimento das necessidades sociais em saúde e na promoção de bem-estar e vida com qualidade para os usuários do sistema com destaque para os que possuem algum problema de saúde que o deixe vulnerável à assistência cotidiana e à uma vida produtiva.

Estruturalmente o dossiê está composto por catorze artigos que discutem temas dos mais diversos, perpassando pela utilização da fitoterapia e seu acesso como uma medida integrativa de saúde; A importância e os desafios éticos do transplante de medula óssea no tratamento e cura de portadores de doença falciforme; Os desafios das famílias com crianças portadoras de leucemia, mais precisamente, a busca de evidências para a assistência à criança com leucemia dando ênfase no impacto familiar em sua dinâmica de vida relativa ao 


\section{Apresentação}

Hegemonia - Revista Eletrônica do Programa de Mestrado em Direitos Humanos, Cidadania e Violência/Ciência Política do Centro Universitário Unieuro

ISSN: 1809-1261

UNIEURO, Brasília, número 27 (Especial), 2019, pp. 1-6.

diagnóstico; O desenvolvimento de biomateriais a base de látex para uso na área da saúde; O uso da fototerapia na aceleração da cicatrização do pé diabético; O desenvolvimento da nanotecnologia aplicada à saúde, e relato das novas possibilidades de inovações tecnologias para diagnóstico de doenças causadas por vírus, por exemplo; Além de estudos sobre os custos entre internações no Sistema Único de Saúde (SUS) e o sistema de autogestão.

Como apresentado, os desafios em saúde são muitos. Aqui, são colocados apenas algumas condições discutidas pelos colaboradores. Sabe-se que diversas outras condições também esperam por reflexões e inovações, as quais devem envolver a gestão e suas novas formas de pensar e fazer saúde, almejando o benefício do maior número possível de pessoas. Até porque, um quadro de adoecimento priva o adoecido do que há de mais importante, seu bem-estar e vida com qualidade.

Boa leitura e boas reflexões!

Aldira Guimarães Duarte e Glécia Virgolino da Silva Luz Organizadoras Brasília, Novembro de 2018 